\title{
Pedagogias do Presente
}

Viviane Castro Camozzato'

'Universidade Estadual do Rio Grande do Sul (UERGS), Bagé/RS - Brasil

RESUMO - Pedagogias do Presente ${ }^{1}$. O objetivo é problematizar as transformações no estado da cultura e, principalmente, suas repercussões no conceito de pedagogia. Procura-se discutir o quanto essas transformações têm sido elementos importantes nas flexões da pedagogia, fazendo com que seja pluralizada em sua denominação e em seus espaços de atuação. Parte-se da hipótese de que a pedagogia procura responder às exigências que cada tempo coloca para a produção de tipos de sujeitos que lhe correspondam, levando adiante o mundo em que vivem. $\mathrm{O}$ argumento é sobre o que é denominado de pedagogias do presente: ou seja, pedagogias que se organizam e funcionam num processo de atualização e reconfiguração constantes. As pedagogias parecem atuar para forjar os sujeitos do presente.

Palavras-chave: Pedagogias do Presente. Transformações Culturais. Estudos Culturais.

ABSTRACT - Pedagogies of Current Times. The aim of this work is to problematise changes in culture and, chiefly, its effects in pedagogy concept. We have sought to discuss the effect of these changes to pedagogies as a way to pluralise its meanings and action spaces. We have drawn on the hypothesis that the pedagogy seeks to fulfil demands for shaping subjects for the world to keep as it is. The argument is about what is called current pedagogies: that is, pedagogies that are organised and work in a process of constant reshaping and updating. Pedagogies seem to act to forge present subjects.

Keywords: Current Pedagogies. Cultural Changes. Cultural Studies.

Educação \& Realidade, Porto Alegre, v. 39, n. 2, p. 573-593, abr./jun. 2014.

Disponível em: <http://www.ufrgs.br/edu_realidade> 
Pedagogias do Presente

Sem dúvida a paisagem mudou (Derrida; Roudinesco, 2004, p. 12).

E se considerarmos que, talvez, a pedagogia tenha perdido "o 'comum' do lugar e do nome” (Foucault, 1999, p. XIV)? E se, ao contrário de um comum, tem-se, agora, muitos lugares e nomes a partir dos quais a pedagogia pode funcionar e operar? E se pensarmos nisso como uma condição das pedagogias do presente, das pedagogias que colocamos em funcionamento neste tempo preciso? Seguindo com estas inquietações, creio que a pulsante cultura contemporânea precisa ser salientada como um importante instrumento de multiplicação dos nomes e lugares em que se ancoram as pedagogias; potente multiplicação dos modos de olhar e ser olhado, de falar e ser falado, implicando numa multiplicação mesma das diferenças. Experiências do e com o presente que vem sofrendo transformações, reconfigurando as faces do mundo, incluindo nós, que dele fazemos parte.

Talvez não se trate de outras pedagogias em atuação, mas de novas ênfases, de reconfigurações, formas atualizadas de funcionamento e de colocar em operação discursos de hoje. É assim que o conceito “[...] nomeia o gesto de uma apreensão, é uma captura” (Derrida; Roudinesco, 2004, p. 14). Está implicado nas estratégias de reformulação a partir das descontinuidades, dos limiares, das mutações, das transformações.

Em relação a tais questões, cabe salientar que infindáveis usos do conceito de pedagogia vêm sendo utilizados e propostos. Trata-se de pedagogias disso, daquilo e daquele outro. De fato, o uso desse conceito vem sendo cada vez mais empregado para mostrar a operacionalidade de discursos específicos em artefatos que se dispõem a educar e produzir determinados tipos de sujeitos. Para exemplificar, cito alguns títulos de livros passíveis de serem encontrados nas livrarias de hoje: Pedagogia do Amor e Pedagogia da Amizade. Bullying - o sofrimento das vítimas e dos agressores, ambos de Gabriel Chalita (Editora Gente, 2005 e 2008); Pedagogia da Cultura Corporal Crítica, de Marcos Garcia Neira e Mario Luiz Ferrari Nunes (Phorte Editora, 2008); Pedagogia da Humanização, de Nelino Azevedo de Mendonça (Paulus Editora, 2008); Pedagogia da Adoção, de Luiz Schettini Filho (Editora Vozes, 2009); Pedagogia do Afeto, de Ivone Padua (editora Wak, 2010); Pedagogia da Transgressão - Um Caminho para o Autoconhecimento, de Ruy Cezar do Espírito Santo (editora Ágora, 10 ed., 2011); Pedagogia do Consumo - Família, Mídia e Educação, de Inez Lemos (Editora Autêntica, 2007); A Pedagogia do Sucesso, de João Batista Araújo e Oliveira (Editora Saraiva, 16 ed., 2005); Pedagogia da Diversidade, de Maria Sirley Santos (Editora Memnon, 2005), entre muitos outros.

Entretanto, em relação ao conjunto de trabalhos que utilizam o conceito de pedagogia em seu título, indago: até que ponto esses trabalhos efetivamente problematizam o próprio conceito de pedagogia, escolhendo as suas heranças e expondo os seus muitos modos de fun- 
cionamento no tempo presente? Tal conceito é tão enunciado e utilizado que poder-se-ia associá-lo ao funcionamento de uma máquina que enuncia infinitas vezes um nome e uma palavra que conceitualmente podem se referir a uma variedade de coisas diferentes. Por um lado, isso pode nos indicar que seu significado parece, frente a essa proliferação enunciativa, não necessitar mais ser problematizado, tornando-o até banal pelo recorrente uso, funcionando como "lugares-comuns do pensamento" (Montero, 2008, p. 90).

Por outro lado, contudo, poderíamos compreender que a multiplicação de pesquisas e bibliografias que adotam a palavra pedagogia nos mostra, também, que há um conjunto de conceitos que despontam - associados ao conceito mesmo de pedagogia - para atuar em um jogo de visibilidades deste tempo. Sociedade da imagem, do espetáculo, do consumo, de controle, etc., são conceitos urdidos frente ao que desponta nos dias de hoje. Reafirmamos certos conceitos, atualizamos e produzimos outros para que falem dos problemas que nos acontecem. Creio que é pelo entendimento compartilhado de que a pedagogia tem íntima relação com a produção das pessoas que ela se encontra, frequentemente, associada aos temas que vão despontando como importantes para serem pensados no tempo presente.

Nessa direção, meu objetivo é problematizar as transformações no conceito de pedagogia, especificando suas articulações com as transformações culturais, vendo e procurando mostrar, por exemplo, o quanto essas tem sido elementos importantes nas flexões da pedagogia, fazendo com que seja pluralizada em sua denominação e em seus espaços de atuação. Parto da hipótese de que a pedagogia procura responder às exigências que cada tempo coloca para a produção de tipos de sujeitos que lhe correspondam, levando adiante o mundo em que vivem, adaptando-se a ele. Ela envolve um conjunto de saberes e práticas que cada indivíduo é incitado a fazer operar sobre si para tornar-se sujeito de determinados discursos. Porém, as transformações na esfera dos saberes e nas tecnologias vêm cada vez mais desalojando as certezas, as permanências, provocando, também, que os sujeitos fluam entre as diversas posições-de-sujeito que lhes são oferecidas a ocupar. Isso tem possibilitado que a pedagogia entre num processo de atualização constante para conectar-se às exigências e necessidades contemporâneas e, assim, investir, de forma sempre atualizada, nesses sujeitos. A tentativa parece ser a de controlar ao máximo o modo e as relações dos sujeitos, incitando-os a implementarem sobre si uma série de pequenos movimentos, que mostram justamente a dispersão desse conceito num conjunto maior que a sociedade tem produzido.

Pretendo marcar, com isso, o modo como desponta um conceito de pedagogia que tem tomado novas formas, tem tido novas ênfases e tem sofrido transformações. Cruza, assim, também uma problematização sobre como e de que modo fomos nos apropriando do conceito de pedagogias culturais - conceito que emergiu na perspectiva dos Es- 
tudos Culturais, como salientarei na seção seguinte - em detrimento do conceito de pedagogia (que, num determinado momento, parece ter sido insuficiente para atuar frente às amplas transformações socioculturais). Do mesmo modo, quero pensar na produtividade e limitações do conceito de pedagogias culturais para argumentar que o conceito de pedagogias pode, talvez, ser utilizado para dar conta das discussões que temos realizado. Sobretudo se considerarmos o quanto, talvez, falar em pedagogias dê conta de toda a problemática sem a necessidade de acoplar o culturais que, segundo Costa (2010), comporta o problema de ser "[...] um termo tautológico se tomado fora do âmbito das análises culturais contemporâneas”, “[...] uma vez que seria difícil pensar-se em alguma pedagogia que não seja produzida pela cultura, sendo, portanto, culturais todas as pedagogias" (Costa, 2010, p. 136-137). Ainda que, todavia, o conceito venha sendo "[...] útil para referirmo-nos àquelas práticas culturais extraescolares que participam de forma incisiva na constituição de sujeitos” (Costa, 2010, p. 137).

Dadas essas considerações gerais, saliento que almejo tratar de noções que comportem a descontinuidade e a transformação para que, no decorrer deste artigo, seja possível compreender melhor as pedagogias "em relação com problemas que são os nossos, com nossa história" (Deleuze; Guattari, 1992, p. 40). O que ofereço, em suma, é uma problematização sobre o conceito de pedagogia, mostrando as necessidades de estilhaçar a pretensão unitária de falar em uma pedagogia e a necessidade de comportar análises que tematizem sobre a multiplicidade do termo em um tempo em que há uma infinidade de estratégias direcionadas ao governo das pessoas: condição cultural que tem deslocado e ampliado o repertório de materiais e discussões de pesquisas no campo educacional.

\section{Entre a Pedagogia e as Pedagogias: transformações no estado da cultura}

Em Cultura \& Sociedade, Raymond Williams (1969) traça e analisa as transformações ocorridas na vida social do fim do século XVIII à década de 1960. Com isso assenta-se a ideia do quão contemporâneos dessas mudanças nós somos. Williams (1969) desenvolve sua argumentação partindo da premissa de que o conceito e a palavra cultura emergiram num determinado momento histórico, no contexto da Revolução Industrial. O seu objetivo, nesse livro, é "mostrar como e porque isso ocorreu" e, ainda, fazer um acompanhamento do "[...] desenvolvimento do conceito até os dias atuais. Ele se apresenta, assim, como um apanhado e uma interpretação de nossas reações intelectuais e sentimentais às transformações que se operaram na sociedade inglesa desde fins do século dezoito" (Williams, 1969, p. 11).

É no escopo dessas discussões que me interesso pelo conceito de pedagogia. Isso porque considero, tal como Williams (1969), que um 
conceito responde às transformações que o vão circundando. Cada conceito, assim, tem uma história, sendo da ordem da construção e, por isso mesmo, precisa ser articulado com as condições em que ele está se fazendo e refazendo. Não cabe tomá-lo como dado ou pronto, estático, mas como um conceito que está em mutação constante. O conceito de pedagogia, nesse sentido, tem uma ampla história e, tal como o conceito de cultura, tão discutido por Williams e inúmeros estudiosos (Hall, 1997; Eagleton, 2005; entre outros), também responde às transformações que foram sendo operadas em nossas sociedades.

A temporalidade escolhida para a problematização neste artigo não é tão ampla quanto a de Williams (1969). Mais especificamente, preocupo-me em tentar circundar o conceito de pedagogia a partir das fecundas e produtivas transformações no estado da cultura e nas relações com os saberes que tem sido perceptíveis a partir de meados da metade do século XX - abordando um espectro temporal que engloba discussões do que tem sido chamado de pós-moderno (Lyotard, 1990; Harvey, 1993; Jameson, 2004), modernidade líquida (Bauman, 2001), hipermodernidade (Lipovetsky, 2004), entre outros. Isso porque, ao problematizar as transformações no conceito de pedagogia, parece-me despontar, como uma condição de possibilidade dessas mesmas transformações, as suas relações com "[...] o estado da cultura após as transformações que afetaram as regras dos jogos da ciência, da literatura e das artes a partir do final do século XIX" (Lyotard, 1990, p. XV). Transformações que tem, conforme Lyotard (1990), íntima relação com a "crise dos relatos". Ora, parece-me também que a pedagogia tem se assentado, desde muito tempo, como uma eficaz relatora: seja quando procura extrair dos comportamentos dos indivíduos saberes para voltar a atuar sobre eles; ou quando, num processo complexo de auto referência constante, tenta revestir a si mesma da legitimidade de ser uma ciência e, por isso, detentora de alguma verdade, dentre outros ${ }^{2}$.

Esse estado da cultura tem posto em questionamento uma série de noções caras à Modernidade, como: o foco na razão, no progresso, e nas verdades da ciência; a crença em um sujeito livre, autônomo, centrado, soberano; as referências aos universais e às certezas, bem como nas metanarrativas explicativas, etc. (Silva, 1999). A incredulidade em relação a essas noções configura, a meu ver, uma condição importante para que o conceito de pedagogia seja questionado em suas pretensões civilizatórias e ligadas à noção de ciência. Afinal, a condição pós-moderna, por outro lado, prioriza o hibridismo, a mistura, o local e o contingente, a incerteza, a parcialidade, o borramento de fronteiras e a descentração, a fragmentação e a indeterminação, etc. (Silva, 1999), tornando possível, por sua vez, um questionamento das concepções "solidamente fincadas na Modernidade e nas ideias modernas" (Silva, 1999, p. 111) que tem gerido e gestado a educação e a pedagogia. Concepções que funcionariam, a princípio, em prol de "formar um ser humano supostamente racional e autônomo e em moldar o cidadão e a ci- 
dadã da moderna democracia representativa", sendo, do mesmo modo, "[...] através desse sujeito racional, autônomo e democrático que se pode chegar ao ideal moderno de uma sociedade racional, progressista e democrática" (Silva, 1999, p. 112).

É em relação a esse conjunto de discussões que, talvez, tenha sido possível colocar sob suspeita a noção de pedagogia, no singular, para pensar em pedagogias, no plural. Transito, portanto, nesta tensão entre a pedagogia unitária e as pedagogias que proliferaram, principalmente, com as transformações no estado da cultura advindas com a condição pós-moderna. Por um lado, essa tensão expõe os choques teóricos que cercam a pedagogia, exibindo a fragilidade de um conjunto de argumentações que insistem que há somente uma pedagogia e, ainda, expõe o quanto a ênfase no singular associa-se, sobretudo, às noções derivadas do pensamento moderno. Por outro lado, colocar acento na pluralidade de pedagogias em funcionamento em nossas sociedades parece-me ir em direção às importantes contribuições do pós-moderno e da virada linguística. Nesse sentido, Veiga-Neto (2003) afirma que dentre as consequências da virada linguística inclui-se o estilhaçamento e a pluralização de termos que vinham sendo empregados de forma unitária e, muitas vezes, ainda de forma maiúscula (como $a$ Linguagem, $a$ Cultura, e também podemos acrescentar $a$ Pedagogia). Embora um possível deslocamento da pedagogia (ou, $\mathrm{d} a$ Pedagogia) às pedagogias coloque em evidência uma "dimensão teórica, intelectual", é preciso ressaltar que "não se reduz a uma questão - nem somente, nem mesmo preferencialmente - epistemológica" (Veiga-Neto, 2003, p. 11). Mais fortemente, “[...] tal deslocamento é inseparável de uma dimensão política em que atuam forças poderosas em busca pela imposição de significados e pela dominação material e simbólica" (Veiga-Neto, 2003, p. 11). Essa dimensão política implica considerar que "[...] as atribuições de significados são, sempre e ao mesmo tempo, uma questão epistemológica e uma questão de poder" (Veiga-Neto, 2003, p. 11). No cerne do compartilhamento da noção de pedagogias, no plural, está o entendimento que privilegio: o da pluralidade.

Retomando Lyotard (1990, p. 3), cabe salientar que o autor expõe dessa maneira a sua hipótese de trabalho:

$$
\begin{aligned}
& \text { [...] o saber muda de estatuto ao mesmo tempo que as socieda- } \\
& \text { des entram na idade dita pós-industrial e as culturas na idade } \\
& \text { dita pós-moderna. Esta passagem começou desde pelo me- } \\
& \text { nos o final dos anos 50, marcando para a Europa o fim de sua } \\
& \text { reconstrução. Foi mais ou menos rápida conforme os países e, } \\
& \text { nos países, conforme os setores de atividade: donde uma dis- } \\
& \text { cronia geral, que não torna fácil o quadro de conjunto. }
\end{aligned}
$$

Ele mesmo abdica de montar qualquer quadro, optando por focar em uma característica principal dos deslocamentos advindos com a condição pós-moderna: a mudança de estatuto do saber nas sociedades informatizadas. Parece-me que a pedagogia está diretamente impli- 
cada nessa mudança de estatuto do saber pois, como Lyotard (1990, p. 4-5) salienta: "Pode-se então esperar uma explosiva exteriorização do saber em relação ao sujeito que sabe (sachant), em qualquer ponto que este se encontre no processo de conhecimento", proporcionando que "O antigo princípio segundo o qual a aquisição do saber é indissociável da formação (Bildung) do espírito, e mesmo da pessoa, cai e cairá cada vez mais em desuso". Com a ênfase nas tecnologias, o saber é diluído na massa informacional que circula na sociedade, sendo exteriorizado e, ao mesmo tempo, acessível e presente na vida das pessoas de variadas maneiras, operando em conjunto com artefatos culturais ${ }^{3}$ que tem contribuído para disseminar os saberes socialmente mais legitimados.

Tendo essas considerações acima à espreita nas movimentações realizadas, posso dizer que, quando me refiro à noção de tempo presente, estou demarcando o estado da cultura atual. Essa escolha temporal se deve, dentre o que recém foi justificado, a dois motivos principais.

Primeiro, ao fato de fazer uma opção interessada em problematizar o conceito de pedagogia a partir das transformações temporalmente mais próximas a nós. Por um lado, isso se justifica frente a enorme quantidade de produções que têm posto em evidência histórias da pedagogia (embora a maioria diga fazer uma História, no singular mesmo). Há, nesse sentido, uma coleção considerável de obras que contam algumas das muitas histórias possíveis sobre a pedagogia. Obras importantes como a de Cambi (1999), Gauthier e Tardif (2010), entre outros, tem estado no meu horizonte para que eu possa compreender o conceito de pedagogia na encruzilhada discursiva que existe sobre ela. Entretanto, de um modo muito mais modesto, não tenho o objetivo e nem o interesse de me juntar às análises que tem esmiuçado a história da pedagogia. Tenho, sim, o objetivo de procurar mostrar que o conceito de pedagogia continua, proximamente a nós, sofrendo transformações nesse tempo em que está operando.

Não trato, assim, da permanência e continuidade no conceito de pedagogia, visando apontar sua origem e possível evolução, ou mesmo sua mudança. Nesse sentido, autores como Foucault (2009, p. 23) têm colocado em destaque conceitos como os de "[...] descontinuidade, de ruptura, de limiar, de limite, de série, de transformação", numa tentativa de afastamento "[...] de todo um jogo de noções que diversificam, cada uma à sua maneira, o tema da continuidade" (p. 23). Foucault (2009) menciona, ainda, a partir das análises de Canguilhem, o quanto os conceitos são atingidos por deslocamentos e transformações (sendo, portanto, cingidos, descontínuos, dispersos, apontando para a diferença e não à unicidade). A movimentação de cada conceito estaria associada à história de seus múltiplos campos de constituição e validade, bem como das sucessivas regras de uso e dos meios teóricos variados que serviram para a sua elaboração (Foucault, 2009). Tais assertivas levam-me a conceber o conceito de pedagogia nas suas condições de produção contemporâneas. 
O segundo motivo para justificar o critério temporal na demarcação aqui destacada é, precisamente, por considerar que este artigo (e a pesquisa a que esta produção deriva) pode se juntar a uma série de outros trabalhos acadêmicos que vêm esmiuçando as estratégias contemporâneas de produção e governo das pessoas. Principalmente, cabe dizer, ao problematizarem as estratégias educativas e pedagógicas postas em operação para produzir comportamentos, mentalidades, racionalidades, etc.

Tal movimentação nas escolhas e modos de compor essa problematização se deve, sobretudo, a esse conjunto de discussões e pesquisas que preciso mencionar mais detidamente. São as que dialogam, na perspectiva dos Estudos Culturais, com o que vem sendo denominado, tautologicamente, de pedagogias culturais - como já comentado. Conceito que tem fomentado um leque amplo de possibilidades para as análises culturais em educação.

No artigo Kindercultura: a construção da infância pelas grandes corporações, Steinberg (1997, p. 101-102) utilizou-se do conceito de pedagogia cultural compreendendo-o a partir da ideia

\begin{abstract}
[...] de que a educação ocorre numa variedade de locais sociais, incluindo a escola, mas não se limitando a ela. Locais pedagógicos são aqueles onde o poder se organiza e se exercita, tais como as bibliotecas, TV, filmes, jornais, revistas, brinquedos, anúncios, videogames, livros, esportes, etc..
\end{abstract}

Tal entendimento tem servido a um conjunto de pesquisas e produções que têm dialogado com a rede de saberes e poderes que atuam no contemporâneo, problematizando o funcionamento, endereçamento e produção de sujeitos que as pedagogias culturais têm forjado. Parece admissível situar o conceito de pedagogias culturais como a expressão de um conjunto de transformações sociais e culturais que tornaram possíveis a sua emergência. Às transformações sociais talvez seja possível afirmar que se acrescentam, também, formulações e reformulações nos conceitos utilizados para descrever e construir a sociedade.

Já no artigo Por uma Pedagogia Crítica da Representação, Giroux e McLaren (1995, p. 144) afirmam: “[...] existe pedagogia em qualquer lugar em que o conhecimento é produzido, em qualquer lugar em que existe a possibilidade de traduzir a experiência e construir verdades". Ou seja, uma multiplicidade de formas de conhecimento que servirão para produzir identidades e subjetividades. Incluindo, assim, um sistema de significação ligado a relações de poder que, ao mesmo tempo, têm borrado as rígidas distinções entre conhecimentos cotidianos, da cultura de massas e, ainda, os escolares.

Como Giroux (1995) refere em outro artigo, intitulado Memória e Pedagogia no Maravilhoso Mundo da Disney, estudos realizados nas décadas de 1980 e 1990 deram importantes contribuições para a pro- 
blematização das relações entre poder e cultura. A partir de análises advindas dos estudos culturais, do pós-modernismo, dos feminismos e pós-colonialismo, esses estudos, segundo o autor, "[...] ao focalizar[em] a resistência cultural como uma forma de luta política, [...] deram uma dimensão teórica a uma nova política da cultura", tornando possível uma redefinição da "[...] gama de textos culturais sujeitos a um questionamento crítico e, ao mesmo tempo, fazendo da cultura popular um objeto sério de crítica e análise social" (Giroux, 1995, p. 133-134). Novos objetos de saber foram incluídos nas pautas que começaram a pôr em questão as políticas culturais implicadas na formação e transformação das pessoas.

A partir da análise dos filmes Bom Dia, Vietnã (1987) e Uma Linda Mulher (1990), ambos da Companhia Disney, Giroux (1995) problematiza o modo como são construídas e reinventadas as relações entre memória, política e identidade, posicionando as mulheres, negros, latinos, e toda uma série de ditos "outros" em posições cristalizadas no jogo das identidades. Ao mesmo tempo, uma política da inocência atravessa essas produções que, embora não tenham como alvo específico o público infantil, tem "[...] o mesmo ethos insidioso da inocência infantil que a Disney Company rigidamente impõe a todos os seus produtos do passado e do presente" (Giroux, 1995, p. 142). Tais filmes, como textos culturais, operam uma multiplicidade de práticas que são pedagógicas e, também, políticas - tornando imperativo um alargamento da pedagogia para englobar os "[...] locais onde a pedagogia do poder é usada para produzir narrativas, representações e estórias particulares sobre quem está autorizado a falar, sob quais condições e no interesse de quem" (Giroux, 1995, p. 154-155). Nota-se, aí, o quanto o entendimento da pedagogia se encontra ampliado nessas produções, operando como um conceito que nos auxilia a pensar, problematizar e indagar o tempo presente.

Parece-me que a ênfase que se tem dado às pedagogias culturais foi uma porta de entrada importante para a ampliação, no Brasil, do entendimento do que se considera pedagogia. Nos depoimentos de pesquisadores que partilham da perspectiva dos Estudos Culturais, colhidos e analisados por Wortmann (2010), transparece a importância da ampliação do pedagógico nos estudos das pedagogias culturais. Tal abordagem e discussão vêm sendo disseminada no País desde meados da década de 1990, como é possível verificar pelas datas das publicações de Steinberg (1997), Giroux e McLaren (1995) e Giroux (1995), citadas anteriormente. Encontramos produções que se referem às pedagogias culturais em todas as regiões do Brasil. Embora seja perceptível, também, que até por sua entrada pelo Rio Grande do Sul (mais especificamente, pela Faculdade de Educação da UFRGS) esse é o Estado que mais tem influenciado e alimentado esses estudos.

No rastro dessas discussões considero, mais explicitamente, que é necessário tensionar o conceito de pedagogia para, daí, articulá-lo à noção de cultura e às fecundas, produtivas e intensas transformações que 
temos vivido. Com isso acredito que é possível situar e compreender melhor as transformações, ressonâncias, reverberações e relações do referido conceito no tempo em que está em funcionamento. Tornando possível, como já salientado, um deslocamento da noção de pedagogia para pedagogias.

Além disso, cabe salientar que o conceito de pedagogia encontra-se em meio a fortes embates em torno dos seus significados. Há grande circulação, concomitantemente, de trabalhos que defendem o estatuto de ciência para a pedagogia. Um exemplo disso pode ser encontrado no artigo Pedagogia como Ciência da Educação: retomando uma discussão necessária (Ferreira, 2010), no qual a autora sistematiza seus argumentos para reiterar a pedagogia como sendo a ciência da educação. Nas palavras da autora:

A compreensão da Pedagogia atual implica a recuperação de um passado que a constituiu. Ao recuperá-lo, está-se buscando re-encontrar os aspectos que possibilitam a compreensão da Pedagogia como ciência da educação. Utilizo 'ciência' no singular porque creio ser ela única, embora em integração contínua com outras ciências. Neste sentido, a pluralização, a meu ver, a desfoca e desqualifica. Ainda que alguns autores sejam incisivos ao proporem essa pluralização, penso que pluralizar pode reforçar uma incompreensão da Pedagogia como ciência da educação, na medida em que isto contribui para, semanticamente, no início, generalizar e, na prática, mais tarde, incitar novamente a pensar que ela é genérica, sem especificidades de estudo, por isto, uma área do conhecimento menor e, como tal, não tratada como ciência (Ferreira, 2010, p. 234).

A ênfase num passado que explicaria o presente e a recuperação e afirmação da legitimidade da pedagogia mediante sua imposição como ciência aparece como justificativas para defender a pedagogia como sendo "a ciência da educação". Uma pluralização que a "desfoca e desqualifica", segundo a autora, e que pode possibilitar que seja pensada como "uma área de conhecimento menor". Essa é uma argumentação recorrente nas defesas da pedagogia como ciência da educação, ou seja, reconhecê-la como ciência para que, em relação às demais áreas do conhecimento, ela compartilhe da mesma validade. Entendo que isso evidencia os embates em torno dos significados deste conceito, mostrando o quanto esse é um campo eivado de disputas interessadas.

Entretanto, é recolhendo argumentos nas inúmeras pesquisas, teses, dissertações, livros e artigos que têm mostrado o forte endereçamento pedagógico dos artefatos culturais que a problematização deste artigo se articula e encontra a sua justificativa. Esse conjunto de pesquisas e os direcionamentos das condutas que cada uma aponta me fazem pensar que, num conjunto, as pedagogias se conectam através das condições e regras de formação que as tem tornado possíveis. Como 
esse conjunto de discussões pode ser pensado e articulado entre si? Evidentemente, o conceito de pedagogias culturais é, como as produções citadas apontam, o principal elo articulador. Articulação no sentido discutido por Wortmann (2005), ao tecer comentário de uma obra da autora Jennifer Daryl Slack, como uma conexão produzida e, por isso, não natural ou essencializada. Uma movimentação que pode envolver três níveis: o epistemológico, o político e o estratégico:

\begin{abstract}
No nível epistemológico, a articulação corresponde a um modo de pensar as estruturas que conhecemos como um jogo de correspondências, não correspondências e contradições, ou como fragmentos constituintes daquilo que nós consideramos serem as suas unidades; no nível político, a articulação é um caminho para colocar em destaque a estrutura e os jogos de poder vinculados a relações de dominação e de subordinação. [...] E, finalmente, em um nível estratégico, a articulação provê mecanismos para configurar a intervenção no interior de uma particular formação, conjuntura ou contexto social (Wortmann, 2005, p. 178-179, grifos da autora).
\end{abstract}

Em relação ao conceito de pedagogia, creio que esses três níveis se sobrepõem o tempo todo. É possível identificar fragmentos que se encontram espalhados em uma série de autores e materiais, correspondências e contradições que mostram articulações provisórias em funcionamento, relações de saber-poder que podem ser destacadas, mecanismos que operam e tornam as especificidades um diferencial das pedagogias do tempo presente, etc. É nesse sentido, também, que cada conceito não é produzido de modo linear, visto que todo "[...] conceito é questão de articulação, corte e superposição" (Deleuze; Guattari, 1992, p. 27). Além disso, "[...] apesar de datados, assinados e batizados, os conceitos têm sua maneira de não morrer, e todavia são submetidos a exigências de renovação, de substituição, de mutação" (Deleuze; Guattari, 1992, p. 16). É assim que cada conceito sofre transformações em decorrência do tempo-espaço em que funciona. $\mathrm{O}$ conceito de pedagogia encontra-se, irremediavelmente, implicado nessas condições.

\title{
Cultura(s) e Pedagogia(s)
}

Para dar início a esta discussão cabe trazer alguns apontamentos sobre o conceito de cultura. No livro A Hermenêutica do Sujeito, Michel Foucault (2004) faz uma significativa consideração sobre o termo cultura para justificar a noção de "cultura de si" como sendo algo que fazia parte da época helenística e romana. Embora um pouco longa, vale a pena expor a citação na íntegra, onde o autor explicita as condições em que se pode falar de cultura:

Primeiramente, quando dispomos de um conjunto de valores que têm entre si um mínimo de coordenação, de 
subordinação, de hierarquia. Pode-se falar de cultura quando atendida uma segunda condição, a saber, que estes valores sejam dados como sendo ao mesmo tempo universais, mas não acessíveis a qualquer um. Terceira condição para que se possa falar de cultura: a fim de que os indivíduos atinjam estes valores, são necessárias certas condutas, precisas e regradas. Mais que isto, são necessários esforços e sacrifícios. Afinal, é necessário mesmo poder consagrar a vida inteira a estes valores para ter acesso a eles. Por fim, a quarta condição para que se possa falar de cultura, é que o acesso a estes valores seja condicionado por procedimentos e técnicas mais ou menos regrados, que tenham sido elaborados, validados, transmitidos, ensinados, e estejam também associados a todo um conjunto de noções, conceitos, teorias, etc., enfim, a todo um campo de saber (Foucault, 2004, p. 220-221).

Acredito que aí encontramos uma abertura para pensar nas relações entre pedagogia(s) e cultura(s). A pedagogia parece-me ser o ponto de articulação importante quando se trata de produzir e incitar uma injunção entre os valores e significados expressos e colocados como mais fortes num tempo-espaço preciso - evidenciando embates pela significação, por ser próprio de uma vontade de pedagogia querer estruturar o campo de ação dos outros nesse mesmo movimento; entre valores universais, porém restritos; entre a meta por atingi-los tendo como exigência certas condutas, esforços e sacrifícios; e quando se trata de estabelecer relação com procedimentos e regras que estejam em funcionamento, juntamente com ensinamentos associados a um campo de saber. Como um conjunto de saberes e práticas, a pedagogia parece ser esse elo articulador entre, de um lado, ensinamentos e, de outro, práticas que são adotadas para que cada um opere sobre si mesmo, fazendo (ou não) com que os ensinamentos - articulados a discursos - de uma cultura atuem e façam parte de cada existência.

A terceira e quarta condições apresentadas por Foucault (2004) para que se possa falar em cultura tratam da questão das condutas, esforços e sacrifícios, assim como dos procedimentos e técnicas "que tenham sido elaborados, validados, transmitidos, ensinados" em "um campo de saber". A ênfase recai, como ele expõe, nos valores a serem aprendidos numa relação que não deixa de acontecer consigo mesmo, por via dos procedimentos e técnicas utilizados para aprender os valores que estiverem em questão. Essa operação sobre si a partir da cultura envolve uma (re)elaboração dos sujeitos consigo.

Para Harris (2000, p. 17, trad. minha) a "[...] cultura é o modo socialmente aprendido de vida que se encontra nas sociedades humanas e que abarca todos os aspectos da vida social, incluídos o pensamento e o comportamento". O autor faz essa declaração ao discutir o controverso argumento de que a cultura é constituída somente por ideias ou, num outro viés, por comportamentos - distinção sustentada por parte considerável de antropólogos contemporâneos, segundo ele. Para o vultoso 
contingente do primeiro grupo "As ideias de nossa mente guiam nosso comportamento” (Harris, 2000, p. 18, tradução minha). O inverso, porém, não acontece. Harris (2000, p. 26) advoga a favor de que "[...] o comportamento e as ideias devem ser vistos como elementos de uma inter-relação". Para os efeitos das hipóteses que sustento essa inter-relação parece-me adequada na medida em que, como salientado a partir de Foucault (2004), as condições para se falar em cultura são variadas, mas interconectadas. Ou seja, se a pedagogia está implicada nas operações que fazem parte da produção das pessoas, ela encontra-se, centralmente, também em contínua relação com a cultura. Contudo, essa relação não deixa de implicar, do mesmo modo, em aprendizagens que se dão sobre atuações sobre si mesmo, produzindo tanto ideias quanto comportamentos.

Ademais, utilizo a concepção de cultura de Costa (2005, p. 109), que a compreende do seguinte modo:

[...] como expressão das formas pelas quais as sociedades dão sentido e organizam suas experiências comuns; cultura como o material de nossas vidas cotidianas, como a base de nossas compreensões corriqueiras. A cultura passa a ser vista tanto como uma forma de vida (ideias, atitudes, linguagens, práticas, instituições e relações de poder), quanto toda uma gama de produções, de artefatos culturais (textos, mercadorias, etc.).

As conexões entre cultura(s) e pedagogia(s), a partir das considerações expostas, parecem-me evidentes. A abertura para o entendimento de que a cultura é produtiva e atuante em muitas esferas e artefatos culturais é uma contribuição importante para que possamos, aqui, tensionar as pedagogias do presente. É uma das suas condições o entendimento ampliado de cultura, num direcionamento em que ela deixa, por sua vez, “[...] de ser domínio exclusivo da erudição, da tradição literária e artística, de padrões estéticos elitizados, e passa a contemplar, também, o gosto das multidões” (Costa, 2005, p. 108). Assim, alça-se uma das mais notáveis características do tempo presente: hoje há a ausência de valores incontestáveis e universais para se erguer julgamentos e hierarquias frente às produções e práticas analisadas a partir de seu viés cultural, ao mesmo tempo em que tem havido "[...] uma mudança vertiginosa das instituições que podem emitir interpretações autorizadas” (Sarlo, 2005, p. 59).

Um exemplo que, a meu ver, engloba as múltiplas “condições” nas quais é possível articular cultura(s) e pedagogia(s) encontra-se na dissertação de mestrado de Prates (2008), onde a autora faz uma instigante análise de como funciona e opera uma pedagogia que orienta e dirige garotas para o consumo no que chama de Complexo W.I.T.C.H. Tal Complexo formou-se, inicialmente, por uma revista e uma série animada direcionada a garotas. Posteriormente, outros artefatos foram sendo incorporados, tornando-se, efetivamente, um Complexo justamente 
Pedagogias do Presente

por enredar as garotas nas suas redes múltiplas: “Ao mesmo tempo em que elas se interessam pelo tema do desenho animado e da Revista, vão sendo dirigidas para o consumo de um incontável número de outros artefatos”, bem como vão "[...] moldando suas condutas de acordo com os preceitos, regras, lições, dicas, modelos, etc. que circulam em todo o Complexo" (Prates, 2008, p. 19). Para tal análise, a autora esmiúça detalhadamente os artefatos e estratégias deste Complexo, analisando, ainda, as convocações presentes para que as garotas invistam sobre si mesmas, transformando-se a partir dos ensinamentos aí presentes.

Uma das principais contribuições da pesquisa de Prates (2008) está em mostrar de forma detalhada o quanto há uma eficiência por parte dos artefatos do Complexo para proporcionar que as garotas pratiquem sobre si algumas das técnicas propostas. Os testes, as matérias dos exemplares da revista, as lições, as recomendações e ensinamentos tornam-se, assim, um conjunto de práticas direcionadas ao governo dessas garotas encaminhando-as, principalmente, ao consumo de mercadorias do Complexo. Um dos artefatos deste Complexo são os chamados Livros Secretos - pequenos livros, de leitura acessível e com prescrições sobre assuntos diversos, como as relações entre meninas e meninos, as dúvidas sobre o amor, sobre como conquistar amigos, como sobreviver na escola, entre outros. Prates (2008, p. 80) comenta que os vê "[...] como manuais que prescrevem formas de viver em consonância com o que cada garota precisa em determinado momento, pois há os dias de fragilidade na escola, de fragilidade na amizade, de fragilidade no amor". Esses Livros Secretos contém muitas orientações, regras e recomendações, oferecendo subsídios para como agir nas situações do dia a dia. Prates (2008, p. 80) identifica uma das estratégias do Complexo, que é "[...] sugerir formas de agir e de ser na busca de solução para determinado problema, ou ainda fazer com que as garotas acabem encontrando alguma carência, detectada nos testes e diversos diálogos". É preciso lembrar, aqui, que criar e/ou apontar uma "falta" é uma estratégia de governo: é reconhecendo a incompletude que se pode voltar a atuar sobre si para preenchê-la a partir de alguma das muitas lições, recomendações, prescrições, etc., disponíveis no contexto social em que se está.

Nesta produção acadêmica aparecem os investimentos para oferecer sentidos e moldar/sugerir experiências, urdir as vidas cotidianas, atravessar os múltiplos artefatos tendo em vista a produção de sujeitos que se associem ao consumo de tudo que circula no referido Complexo. Com isso espero chamar a atenção para a dessacralização dos cânones nas relações entre cultura(s) e pedagogia(s) que o entendimento de cultura a partir dos Estudos Culturais nos proporciona. Sob a ótica da cultura, digamos que materiais mais próximos do que é convencionalmente chamado de cultura popular passaram a ser considerados como objeto de estudo, “[...] oportunizando seu esquadrinhamento e análise" como produtores de significados mergulhados "em redes de poder 
e verdade, em discursos circulantes, através dos quais se legitimam determinadas representações" (Costa, 2005, p. 114-115), convocações, lições, práticas, etc. Estando implicados, portanto, nos sujeitos do presente que se está introduzindo e adaptando ao mundo.

Como Prates (2008) explica, no Complexo W.I.T.C.H. a magia é utilizada como um "chamariz" para convocar ao consumo dos produtos anunciados no Complexo. Depois de capturadas as garotas diminuem seu interesse pela magia e voltam-se mais ao seguimento das incontáveis recomendações postuladas pelo Complexo. Desse jeito elas se tornam "[...] consumidoras não só de artefatos, como roupas, cosméticos, bijuterias, materiais escolares, produtos esotéricos, produtos anunciados dentro da Revista pelos patrocinadores", mas, principalmente, de "estilos e modos de ser" (Prates, 2008, p. 91). A autora assinala, ainda, que:

O Complexo W.I.T.C.H. inscreve-se neste tempo e traz consigo essa característica volátil e descartável que espetaculariza a magia ao mesmo tempo que controla a vida das jovens garotas. Nesta conjuntura, o Complexo constitui-se num rico, fascinante e envolvente artefato cultural, que coloca em circulação discursos que vão forjando certos tipos de identidades, regulando a vida das meninas e levando-as ao consumo de diversos artigos (Prates, 2008, p. 93).

As análises do Complexo W.I.T.C.H. realizadas na dissertação de mestrado de Prates (2008) nos mostram a fecundidade das pedagogias inscritas neste tempo. Do mesmo modo, a autora detalha os artefatos culturais e as formas de vida que estes artefatos tentam forjar ao utilizarem de práticas de si que buscam incitar que as jovens garotas operem sobre si mesmas um conjunto de transformações. No cotidiano das experiências comuns, na formulação dos modos de compreender o mundo, a si e aos outros, culturas e pedagogias estão articuladas e em funcionamento.

Nas discussões sobre as pedagogias do presente atravessa um foco comum: elas estão centralmente articuladas às práticas sobre si. É preciso agir sobre si mesmo para que os discursos sejam implementados. Há, desse modo, uma dupla articulação: de um lado, convocações para que os indivíduos ocupem determinadas posições-de-sujeito, atuando sobre si; de outro, a resposta a essas mesmas convocações mediante a adoção de práticas que associem os indivíduos aos saberes.

Falamos em pedagogia da mídia, pedagogia escolar, pedagogia do consumo, pedagogia radical, pedagogia do corpo, entre outros, mas será que todas não se relacionam a uma pedagogia que tem como foco primordial as relações consigo? Dito de outro modo: será que o sucesso de cada uma das pedagogias que produzimos e multiplicamos no tempo presente não está diretamente relacionada com os seus usos diários em nossas vidas, atuando sobre nós mesmos, produzindo-nos a partir dos saberes e práticas que passamos a assumir como nossos e que nos

Educação \& Realidade, Porto Alegre, v. 39, n. 2, p. 573-593, abr./jun. 2014.

Disponível em: <http://www.ufrgs.br/edu_realidade> 
inscrevem, ademais, como sujeitos de determinados discursos? A resposta afirmativa a estas questões nos encaminham a pensar que lidamos com pedagogias do presente: pedagogias que tem se transformado a partir das condições do presente, sendo esse um imperativo e uma condição para que elas tentem cumprir a sua "missão" de produzir sujeitos conectados ao tempo em questão.

\title{
Sujeitos do Presente
}

Albuquerque Júnior (2008, p. 22) explicita que,

\begin{abstract}
[...] vivemos em sociedades e culturas em que uma multiplicidade de pedagogias opera no cotidiano, visando elaborar subjetividades, produzir identidades, adestrar e dirigir corpos e gestos, interditar, permitir e incitar ou ensinar hábitos, costumes e habilidades, traçar interditos, marcar diferenças entre o admitido e o excluído, valorar diferencialmente e hierarquicamente gostos, preferências, opções, pertencimentos, etc. Estas pedagogias implicam, tal como aquelas praticadas no espaço escolar, a demarcação de fronteiras simbólicas, imaginárias e até físicas.
\end{abstract}

É preciso destacar, aqui, como compreendo o tema das fronteiras. Comumente se aceita a ideia de que as fronteiras aludem, especialmente, a limites territoriais entre estados, cidades, continentes. Espaços físicos, pouco intercambiáveis, naturalizados. Articular o tema das pedagogias e das fronteiras, todavia, possibilita compreender que as fronteiras são “[...] construções de sentido, fazendo parte do jogo social das representações que estabelece classificações, hierarquias e limites, guiando o olhar e a apreciação sobre o mundo" (Pesavento, 2002, p. 36). As pedagogias, nesse sentido, agem para construir fronteiras, produzir uma certa ordenação no mundo e nas pessoas que o habitam. Contudo, são fronteiras móveis, que se chocam umas com as outras e não resistem inertes.

A um só tempo, o tema das fronteiras parece evidenciar tanto a construção de limites e delimitações quanto a condição mesma de habitar um terceiro espaço, um espaço outro. Ora, as fronteiras podem ser pensadas, ainda, como a emergência de espaços abertos ao porvir, ao que Larrosa (2001, p. 286) nomeia como “[...] nossa relação com aquilo que não se pode antecipar, nem projetar, nem prever, nem predizer, nem prescrever”, bem como “[...] com aquilo que não se fabrica, mas que nasce [...], com aquilo que escapa à medida de nosso saber, de nosso poder e de nossa vontade". Parece-me que é nesse limiar que se encontram as múltiplas pedagogias do presente. Apesar da vontade de fixar, controlar, construir um gestual particular para a obtenção de certos efeitos específicos, o reiteradamente planejado não cessa de ser desfeito. Dito de outra forma, o que alimenta as pedagogias é a intencionalidade, sempre reiterada, mas, ao mesmo tempo, nem sempre atingida. 
Aliás, é justamente essa condição própria das pedagogias que as tornam cada dia mais necessárias quando se trata de buscar construir condutas, gestos, comportamentos, modos de pensar, enfim, sujeitos que se inscrevam nas marcas e condições do tempo-espaço que habitam e vivem. Essa inscrição nas marcas do tempo-espaço em questão precisa ser ressaltada. Émile Planchard (1962, p. 73), que foi um pedagogo belga radicado em Portugal, no livro Introdução à Pedagogia, assinala que "Uma evolução pedagógica produz-se fatalmente, ligada às próprias modificações que se sucedem nas coletividades humanas”. E comenta ainda:

A educação, na nossa época como em qualquer outro período do passado, visa inserir a criança numa sociedade determinada. Isso supõe uma adaptação ao passado dessa sociedade, à herança material e espiritual que se transmite de geração em geração. Isso postula igualmente uma preparação para as exigências do tempo presente. Toda educação comporta, portanto, algo de permanente e algo de transitório, algo de antigo e de novo. É preciso ser do seu tempo, mas também de todos os tempos (Planchard, 1962, p. 74).

E mais:

A nossa intenção não é fazer um inventário sociológico do nosso tempo, mas simplesmente chamar a atenção para as profundas mudanças que afectaram o mundo e para a rapidez da sua sucessão. Sob todas as suas formas, em todas as suas funções, a sociedade mudou. Tais modificações exigem de cada um dos seus membros, em matéria de saber, de capacidades, de hábitos, de atitudes, numa palavra, de educação, uma preparação escolar muito diferente da de outrora (Planchard, 1962, p. 77).

“Inserir a criança em uma sociedade”, “[...] preparação para as exigências do tempo presente", "profundas mudanças que afectaram o mundo", “a sociedade mudou”, etc. Nessas afirmações de Planchard (1962) aparece a necessidade de uma leitura e interpretação do tempo presente, sendo essa uma forma de produzir sujeitos que habitem esse mesmo mundo, exigindo, para tanto, "uma preparação escolar muito diferente da de outrora”. Importa ressaltar que Planchard (1962) estabelece as suas discussões privilegiando a pedagogia escolar. É assim que, embora ele reconheça, já há mais de cinquenta anos atrás, as mudanças amplamente perceptíveis na sociedade, ele não conseguia visualizar, ainda, a pedagogia para além da escola. Ele afirma que "O mundo exterior penetra profundamente na casa pelo rádio, pela televisão, pelos discos e pelas revistas" (Planchard, 1962, p. 75). Chega a recomendar que a escola deva utilizar essas tecnologias para se tornar mais atrativa aos estudantes, estabelecendo uma conexão com elas (Planchard, 1962). Contudo, não articula um entendimento ampliado sobre a peda- 
gogia, para além do estritamente escolar. Ao que parece ainda não estavam presentes as condições de possibilidade para esta discussão.

Além do mais, cabe pensar no tempo presente, por sua vez, como não sendo escolhido por nós. Um tempo arbitrário e que pode apenas ser compreendido como contingente e provisório. Um tempo que "[...] escorre constantemente em nossas mãos, resistindo a qualquer uma das nossas tentativas de fixá-lo, de solidificá-lo, de traçar a sua forma e o seu perfil" (Larrosa, 2004, p. 33). É assim que as pedagogias do presente podem, também, ser associadas à liquidez, ao que escorre e toma novas formas móveis, instáveis, mutantes.

Os alvos das pedagogias do presente, nesse sentido, são sujeitos ao tempo preciso que habitam e se constituem, sendo parte integrante desse mesmo tempo. Obviamente, é de se considerar que vivemos num tempo disjuntivo, em que as pessoas circulam por muitos tempos entrecruzados. Contudo, há um aspecto que precisa ser destacado: “[...] o mundo pós-moderno produz não apenas uma economia, um modo de produção e uma sociedade muito peculiares", mas também "constitui sujeitos de um certo tipo, pessoas pós-modernas" (Costa, 2010, p. 133). Os sujeitos do presente são sujeitos às condições culturais do presente. É pelas pedagogias tentarem corresponder às exigências sociais de cada tempo-espaço que elas precisam ser pensadas em relação aos tipos de sujeitos que querem produzir. Afinal, há "[...] sinais indiscutíveis da vasta e crescente influência dos dados sociais na vida pedagógica" (Planchard, 1962, p. 84). Problematizar o conceito de pedagogia e vê-lo inscrito com as marcas do estado da cultura em que ele está operando parece-me, sobretudo, uma necessidade.

A este respeito, o artigo de Momo e Costa (2010) é elucidativo e aborda, a partir de um recorte de pesquisas realizadas em escolas públicas da periferia de Porto Alegre, as articulações entre escola e cultura contemporânea. Ao partirem da noção de que a infância é uma construção operada na cultura, na sociedade e na história e, portanto, sujeita a transformações, descrevem cuidadosamente as marcas que compõem as crianças escolares do tempo presente, imersas em uma cultura pós-moderna. A força da mídia e do consumo na composição de uma infância pós-moderna aparece no artigo e, com isso, os movimentos operados pelas crianças para mergulharem nas características do mundo contemporâneo que inclui, entre outras, a ênfase na visibilidade, na descartabilidade, na efemeridade, na ambivalência e na superficialidade, etc. (Momo; Costa, 2010).

Transparece que há uma multiplicidade de pedagogias atravessando e compondo o cotidiano das crianças citadas por Momo e Costa (2010), fazendo-as estarem em uma movimentação constante. Por isso as autoras utilizam-se da metáfora "incansáveis mutantes", ou seja, crianças que se atém a significados cambiáveis a partir dos ícones das mercadorias, dos astros em evidência, etc., transformando-se a partir disso. Como explicitam: 
Na medida em que esses ícones se caracterizam pela provisoriedade, instantaneidade e efemeridade, as crianças que compõem suas vidas, de algum modo, entremeadas com eles também acabam inventando um modo de viver provisório, instantâneo, cambiante e efêmero (Momo; Costa, 2010, p. 972).

A invenção deste "modo de viver provisório, instantâneo, cambiante e efêmero" exige, a cada vez, pedagogias que compreendam as dinâmicas que sustentam essas refinadas construções de subjetividades. Pedagogias provisórias e abertas para sofrerem, também, incansáveis mutações, uma vez que lhes compete fazerem-se atraentes aos sujeitos inscritos no tempo presente, como Planchard (1962) já indicava. Talvez essa seja, atualmente, uma das mais importantes condições para que as pedagogias persistam em direção ao seu principal objetivo: tornar as pessoas sujeitas a elas. Por tudo isso, creio que ao pensar no conceito de pedagogia seja necessário ajustar o olhar, compreender as marcas e transformações do tempo de seu funcionamento e, quem sabe, abrir-se às novas e inquietantes discussões que esse movimento pode propiciar às nossas pesquisas e ao campo educacional.

Recebido em 18 de outubro de 2012 Aprovado em 07 de dezembro de 2012

\section{Notas}

1 A pesquisa da qual este artigo é resultado contou com o apoio financeiro do CNPq (Bolsa de Doutorado e Bolsa de Estágio de Doutorado no Exterior).

2 Cabe salientar que há muitos embates em torno das definições do conceito de pedagogia. Sugiro a leitura de Houssaye et al. (2004) para uma incursão a essas disputas.

3 Por artefato cultural compreendo um objeto que tem, em torno de si, significados culturais construídos mediante embates por determinados significados associados a relações de poder. Du Gay et al. (1997) analisam o Walkman da Sony e demonstram o processo de produção desse objeto. Produção esta que ocorre tanto na sua forma material quanto cultural, visto que passam a ser acoplados a esse objeto um conjunto de significados que o identificam e o tornam reconhecido.

\section{Referências}

ALBUQUERQUE JÚNIOR, Durval Muniz de. Pedagogia: a arte de erigir fronteiras. In: BUJES, Maria Isabel Edelweiss; BONIN, Iara Tatiana (Org.). Pedagogias sem Fronteiras. Canoas: Ed. ULBRA, 2010. P. 21-31.

BAUMAN, Zygmunt. Modernidade Líquida. Tradução de Plínio Dentzien. Rio de Janeiro: Jorge Zahar, 2001.

CAMBI, Franco. História da Pedagogia. Tradução de Álvaro Lorencini. São Paulo: EDUSP, 1999. 
COSTA, Marisa Vorraber. Estudos Culturais e Educação - um panorama. In: SILVEIRA, Rosa Maria Hessel (Org.). Cultura, Poder e Educação: um debate sobre Estudos Culturais em Educação. Canoas: Ed. ULBRA, 2005. P. 107-120.

COSTA, Marisa Vorraber. Sobre a Contribuição das Análises Culturais para a Formação de Professores no Início do Século XXI. Educar em Revista (Impresso), v. 37, n. 37, p. 129-152, ago./maio 2010.

DELEUZE, Gilles; GUATTARI, Félix. O que é a Filosofia? Tradução de Bento Prado Jr e Alberto Alonso Muñoz. Rio de Janeiro: Ed. 34, 1992.

DERRIDA, Jacques; ROUDINESCO, Elisabeth. De que Amanhã: diálogo. Tradução de André Telles. Rio de Janeiro: Jorge Zahar, 2004.

DU GAY, Paul et al. Doing Cultural Studies. The Story of the Sony Walkman. London: Sage, 1997.

EAGLETON, Terry. A Idéia de Cultura. Tradução de Sandra Castello. São Paulo: UNESP, 2005.

FERREIRA, Liliana Soares. Pedagogia como Ciência da Educação: retomando uma discussão necessária. Revista Brasileira de Estudos Pedagógicos, Brasília, v. 91, n. 227, p. 233-251, jan./abr. 2010.

FOUCAULT, Michel. Prefácio. In: FOUCAULT, Michel. As Palavras e as Coisas. Tradução de Salma Tannus Muchail. 8. ed. São Paulo: Martins Fontes, 1999. P. IX-XXII.

FOUCAULT, Michel. A Hermenêutica do Sujeito. Tradução de Márcio Alves da Fonseca e Salma Tannus Muchail. São Paulo: Martins Fontes, 2004.

FOUCAULT, Michel. A Arqueologia do Saber. Tradução de Luiz Felipe Baeta Neves. 7. ed. Rio de Janeiro: Forense Universitária, 2009.

GAUTHIER, Clemont; TARDIF, Maurice. A Pedagogia: teorias e práticas da antiguidade aos nossos dias. Petrópolis: Vozes, 2010.

GIROUX, Henry. Memória e Pedagogia no Maravilhoso Mundo da Disney. In: SILVA, Tomaz Tadeu da (Org.). Alienígenas na Sala de Aula. Uma introdução aos estudos culturais em educação. Petrópolis: Vozes, 1995. P. 133-158.

GIROUX, Henry A.; McLAREN, Peter. Por uma Pedagogia Crítica da Representação. In: SILVA, Tomaz Tadeu da; MOREIRA, Antônio Flávio (Org.). Territórios Contestados: o currículo e os novos mapas políticos e culturais. Petrópolis: Vozes, 1995. P. 144-158.

HALL, Stuart. A Centralidade da Cultura: notas sobre as revoluções culturais do nosso tempo. Educação \& Realidade, Porto Alegre, v. 22, n. 2, p. 15-46, jul./ dez. 1997.

HARRIS, Marvin. ¿Qué es (son) la(s) Cultura(?). In: HARRIS, Marvin. Teorías Sobre la Cultura en la Era Posmoderna. Barcelona: Crítica, 2000. P. 17-27.

HARVEY, David. Condição Pós-moderna: uma pesquisa sobre as origens da mudança cultural. Tradução de Adail Ubirajara Sobral e Mara Stela Gonçalves. São Paulo: Loyola, 1993.

HOUSSAYE, Jean et al. Manifesto a Favor dos Pedagogos. Tradução de Vanise Dresch. Porto Alegre: Artmed, 2004.

JAMESON, Fredric. Pós-modernismo: a lógica cultural do capitalismo tardio. Tradução de Maria Elisa Cevasco e Iná Camargo Costa. São Paulo: Ática, 2004.

LARROSA, Jorge. Dar a Palavra. Notas para uma dialógica da transmissão. In: LARROSA, Jorge; SKLIAR, Carlos (Org.). Habitantes de Babel: políticas e poéticas da diferença. Belo Horizonte: Autêntica, 2001. P. 281-296. 
LARROSA, Jorge. A Operação Ensaio: sobre o ensaiar e o ensaiar-se no pensamento, na escrita e na vida. Educação \& Realidade, Porto Alegre, v. 29, n. 1, p. 27-43, jan./jun. 2004.

LIPOVETSKY, Gillles. Os Tempos Hipermodernos. Tradução de Mário Vilela. São Paulo: Editora Barcarolla, 2004.

LYOTARD, Jean-François. O Pós-moderno. Tradução de Ricardo Correia Barbosa. 3. ed. Rio de Janeiro: José Olympio, 1990.

MOMO, Mariangela; COSTA, Marisa Vorraber. Crianças Escolares do Início do Século XXI: para se pensar uma infância pós-moderna. Cadernos de Pesquisa, v. 40, n. 141, p. 965-991, set./dez. 2010.

MONTERO, Rosa. A Louca da Casa. Tradução de Paulina Wacht; Ari Roitman. Rio de Janeiro: Agir, 2008.

PESAVENTO, Sandra Jatahy. Além das Fronteiras. In: MARTINS, Maria Helena (Org.). Fronteiras Culturais. São Paulo: Ateliê Editorial, 2002. P. 35-39.

PLANCHARD, Émile. Introdução à Pedagogia. Coimbra: Coimbra editora, 1962. PRATES, Camille Jacques. O Complexo W.I.T.C.H. Acionando a Magia para Formar Garotinhas nas Redes do Consumo. Canoas: ULBRA, 2008. 189 f. Dissertação (Mestrado em Educação) - Programa de Pós-Graduação em Educação, Faculdade de Educação, Universidade Luterana do Brasil, Canoas, 2008.

SARLO, Beatriz. Tempo Presente: notas sobre a mudança de uma cultura. Tradução de Luís Carlos Cabral. Rio de Janeiro: José Olympio, 2005.

SILVA, Tomaz Tadeu da. Documentos de Identidade. Uma introdução às teorias do currículo. Belo Horizonte: Autêntica, 1999.

STEINBERG, Shirley R. Kindercultura: a construção da infância pelas grandes corporações. In: SILVA, Luiz Heron da; AZEVEDO, José Clóvis de; SANTOS, Edmilson Santos dos (Org.). Identidade Social e a Construção do Conhecimento. Porto Alegre: SMED, 1997. P. 98-145.

VEIGA-NETO, Alfredo. Cultura, Culturas e Educação. Revista Brasileira de Educação, Rio de Janeiro, v. 23, n.23, p. 5-15, maio/ago. 2003.

WILLIAMS, Raymond. Cultura e Sociedade: 1780-1950. Tradução de Leônidas H. B. Hegenberg, Octanny Silveira da Mota e Anísio Teixeira. São Paulo: Companhia Editora Nacional, 1969.

WORTMANN, Maria Lúcia Castagna. Algumas Considerações sobre a Articulação entre Estudos Culturais e Educação (e sobre algumas outras mais). In: SILVEIRA, Rosa Maria Hessel (Org.). Cultura, Educação e Sociedade - Um debate sobre Estudos Culturais e Educação. Canoas: Ed. ULBRA, 2005. P. 165-181.

WORTMANN, Maria Lúcia Castagna. (Re)inventando a Educação a partir dos Estudos Culturais: notas sobre a emergência da proposta de articulação entre esses dois campos no ambiente universitário gaúcho. Porto Alegre, 2010. $29 \mathrm{f}$. (Texto digitado).

Viviane Castro Camozzato é licenciada em Pedagogia, mestre e doutora em Educação pela UFRGS. Professora do curso de Pedagogia da Universidade Estadual do Rio Grande do Sul (Uergs) - Unidade Bagé. Coordenadora do Grupo de Pesquisa Educação, Culturas e Pedagogias Contemporâneas e pesquisadora do Núcleo de Estudos sobre Currículo, Cultura e Sociedade (NECCSO).

E-mail: vicamozzato@gmail.com

Educação \& Realidade, Porto Alegre, v. 39, n. 2, p. 573-593, abr./jun. 2014.

Disponível em: <http://www.ufrgs.br/edu_realidade> 